\title{
Effects of Oil Spill on Activities of Enzymes( SOD, GOT and AHH) in the Shrimp Penaeus Vannamei
}

\author{
Hong-wei WANG ${ }^{1,2}$, Fang CAI ${ }^{3}$, Chun-long $\mathrm{ZHAO}^{4 *}$, Ya-ping MA ${ }^{5}$, Jing-mei LIU $^{6}$, Yu FAN ${ }^{1}$ \\ ${ }^{1}$ The Key Laboratory of Zoological Systematics and Application, College of Life Science, Hebei University, Baoding, P.R. China \\ 2. South China Institute of Environmental Sciences, MEP, Guangzhou, P.R .China \\ 3. Plant protection station of Beijing City, Beijing, P.R .China \\ 4. Hebei Ocean \& Fishery Sciences Research Institute, Qinhuangdao, P.R .China \\ 5. Huanggang Institute of Fisheries Science, Hubei Huanggang, P.R .China \\ 6. Qinhuangdao National Aquatic germplasm resources protection area management office, Qinhuangdao, P.R .China
}

\begin{abstract}
With the Penaeus vannamei as experiment object, study the effect of oil on activities of enzymes (SOD, GOT and AHH) in the shrimp $P$. vannamei in different oil concentrations and time. Analyze the change of enzyme activity of shrimp polluted by oil through microplate reader and reagent. The results show that different concentrations of oil will have different influence on three enzymes, and with the increase of concentrations of oil the activities of three enzymes were increased than before. But continue to increase, the activity of SOD decreased, and the activity of monitoring indexes to display the effect of marine oil spill to the activities of physiological and biochemical in P. vannamei.
\end{abstract}

\section{Introduction}

Pollution to the marine environment caused by marine oil spill can affect the aquatic product quality and food safety through the food chain. The activities of SOD, AHH and GOT were elected to be the biochemical indicators to study the influence of marine oil spill on $P$. vannamei. Although the various table text styles are provided. The formatter will need to create these components, incorporating the applicable criteria that follow.

\section{Materials And Methods}

P. vannamei was taken from Tanghai County in Tangshan city of Hebei province, ten Caspian sea farms, size 5-7 cm. The oil concentrations of experimental group were divided into blank control group, $100 \mathrm{mg} / \mathrm{L}$ and $1000 \mathrm{mg} / \mathrm{L}$, three gradients. Mix oil and sea water were directly shocked during the test. After homogeneous mixing, put $P$. vannamei into that mixed solution and observed them. Use the prepared kit to experiment text the activities of SOD, $\mathrm{AHH}$ and GOT in the shrimps under different concentrations.

\section{Results}

\subsection{The activities of enzymes in gut}

In the determination of enzyme activity results, in the initial, three kinds of enzyme activity has a significant reduction, so oil has certain inhibitory effect on three enzymes at an early stage. But with the increase of oil concentration, three kinds of enzyme activity have significantly improvement. In other words, through the cultivation of oil, oil induced three enzymes on the body, and improved their activities.

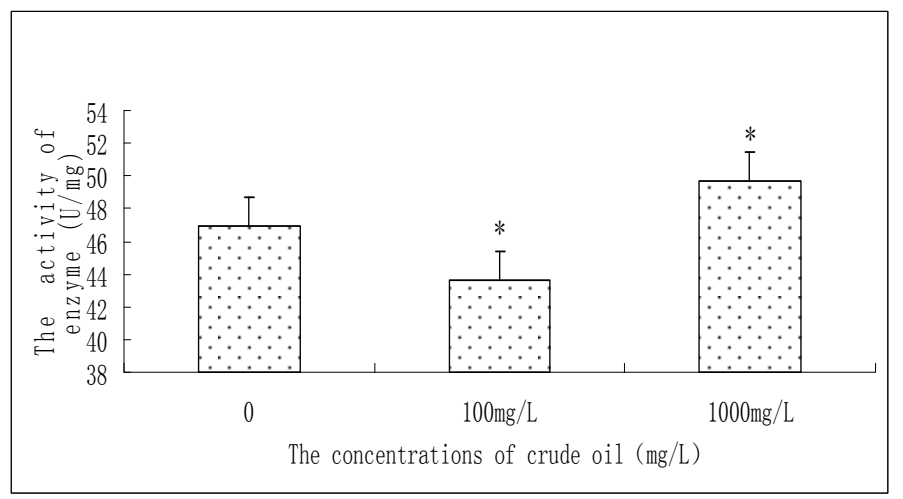

Fig. 1-1 The Activities of SOD in gut of P. vannamei

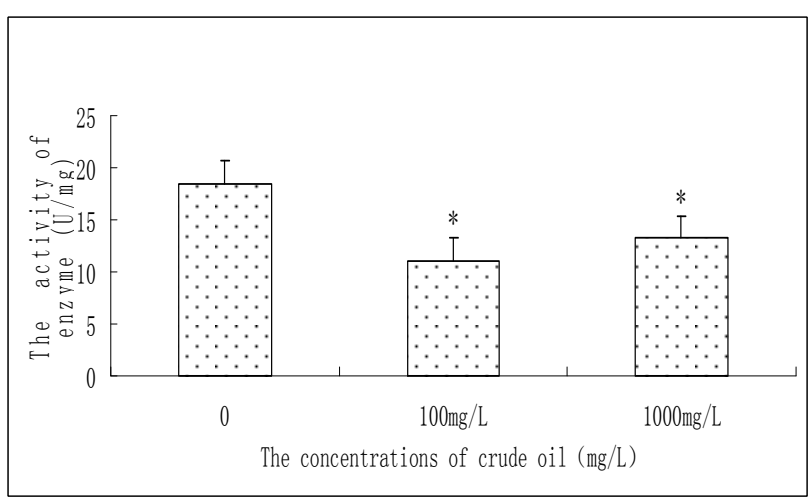

Fig. 1-2 The Activities of GOT in gut of $P$. vannamei 


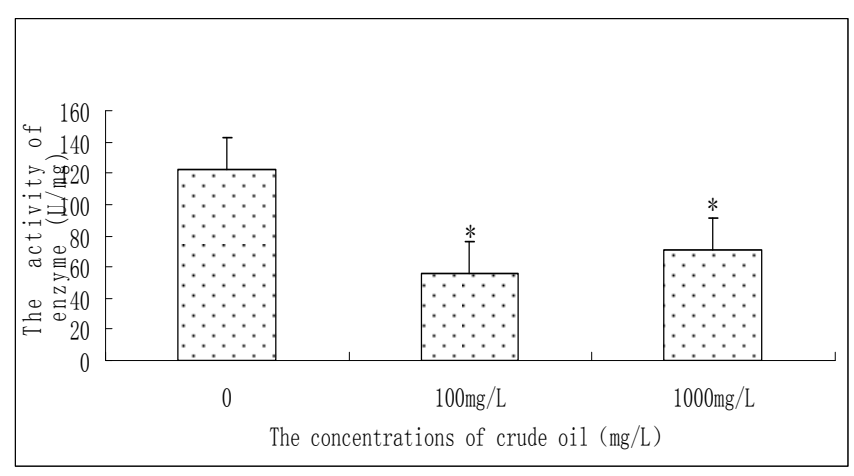

Fig. 1-3 The Activities of AHH in gut of P. vannamei

\subsection{The activities of enzymes in hepatopancreas}

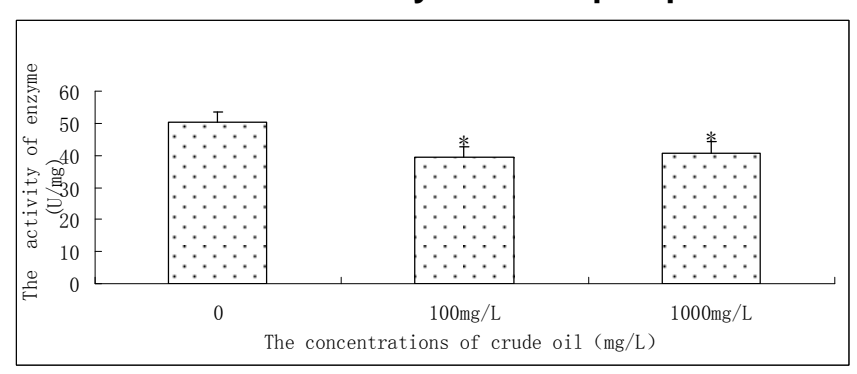

Fig. 2-1 The Activities of SOD in hepatopancreas of $P$.

$$
\text { vannamei }
$$

Both the experimental group low concentration and high concentration are significant different form control group, SOD enzyme activity of the experimental groups were significantly lower than the control group, SOD enzyme activity with high oil concentration is slightly higher than that with low oil concentration.

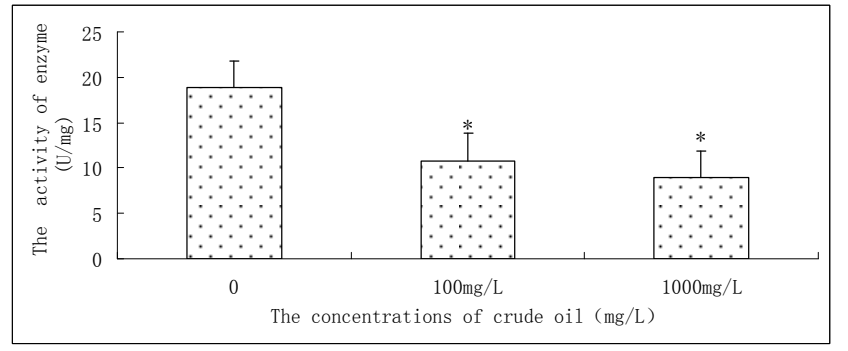

Fig. 2-2 The Activities of GOT in hepatopancreas of $P$.

vannamei

Both the experimental group low concentration and high concentration are significant different form control group, GOT enzyme activity of the experimental groups were lower than the control group, GOT enzyme activity with high oil concentration is lower than that with low oil concentration.

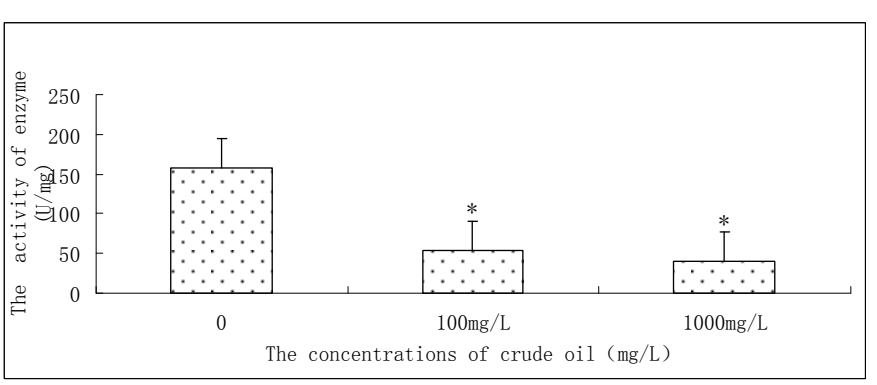

Fig. 2-3 The Activities of AHH in hepatopancreas of $P$.

vannamei

Both the experimental group low concentration and high concentration are significant different form control group, $\mathrm{AHH}$ enzyme activity of the experimental groups were lower than the control group, AHH enzyme activity with high oil concentration is lower than that with low oil concentration.

\subsection{The activities of enzymes in stomach}

Using enzyme standard meter and three kinds of enzyme kit measured gastric three kinds of enzyme activity, including SOD,AHH and GOT, compared with the prawn that cultivated in the pool of no oil, to detect the change of enzyme activity.

When there is oil pollution of cells of the stomach, oil leads to body's DNA fractures lipid, peroxidation enzyme inactivation and a series of oxygen stress, seriously affect the lipid oxidation in the body. The results of the stomach SOD enzyme activity determination said that the oil's influence on SOD is significant $(P<0.01)$, SOD are influenced by the oil pollution and induced synthesis in a certain amount of time, content has a certain degree of increase, but with the increase of oil concentration, there will be a parabolic which is from sharp to blunt.

After the oil flow into the water, oil had an effect on the activity of two enzymes in shrimp body stomach, GOT and AHH's activity occurred a significant reduction, but with the increase of oil concentration, enzyme activity were improved, along with the rising of the concentrations of oil increased. Oil had an effect on two enzymes, affect the enzyme activity. With the increase of concentration of oil, also has induced effect on the enzyme activity.

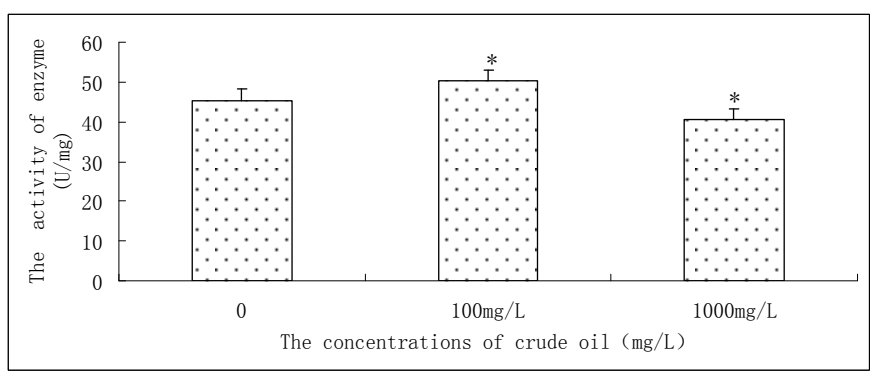

Fig. 3-1 The Activities of SOD in stomach of $P$. vannamei 


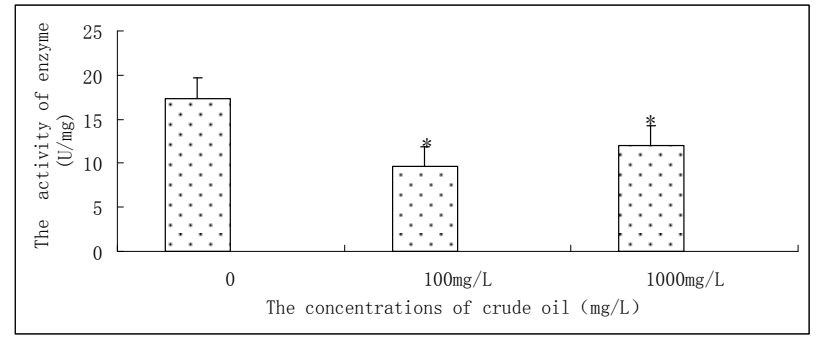

Fig. 3-2 The Activities of GOT in stomach of $P$. vannamei

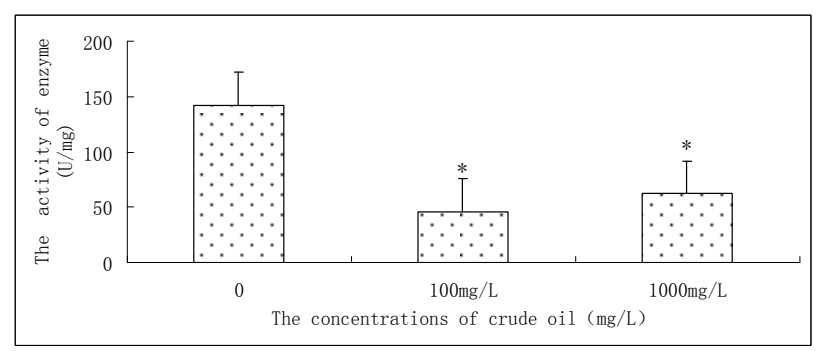

Fig. 3-3 The Activities of AHH in stomach of $P$. vannamei

\subsection{The activities of enzymes in muscle}

The chart shows that prawn muscle's AHH activity first decreases and then increases, may be due to the ability of the enzyme metabolism of exogenous compounds in muscle is saturated, caused the shrimp to occur toxic reaction, and the activity of AHH reduced. The higher of oil concentration, the faster of toxic reaction, so although performance poisoning in high concentration, but $\mathrm{AHH}$ enzyme activity is low, concentration is on the high side.

In the similar way, GOT activity and SOD are first decreases and then increases, the same as AHH, but SOD enzyme activity shows a sharp rise and acuter than the control group when the oil's concentration is high, the reason may be that although the high concentrations oil made the enzyme occur rapid poisoning deactivation, the rise of GOT、AHH activity make the substrate increase gradually and occur compensatory effect so as to the rapid increase of SOD activity. Although low concentration also appears compensation effect, low enough to compete the poisoning effect. So when concentration is low, enzyme activity is low.

Compare $\mathrm{AHH}$ to the results of Bogovski' S experiment which Crude oil present induction phenomenon to $\mathrm{AHH}$ and $\mathrm{AHH}$ enzymes present linear change as the improvement of oil concentration, this experiment has a lower trend, maybe that is because experiment's concentration change is too big so as to beyond the prawn's bear range. Compare SOD to the results of Wang fang's experiment, we know that SOD increased with the increase of oil's concentration, the same as our experiment's result, due to SOD has the balance function of biological oxidation and oxidation process in the body, and SOD can transform intracellular superoxide anion free radical, making the cell aging speed slow down.

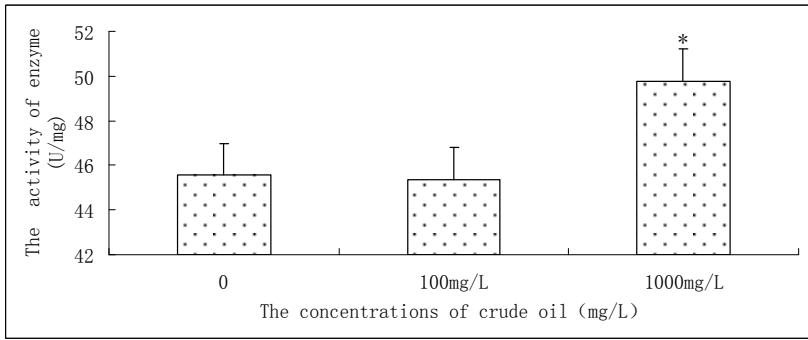

Fig. 4-1 The Activities of SOD in muscle of $P$. vannamei

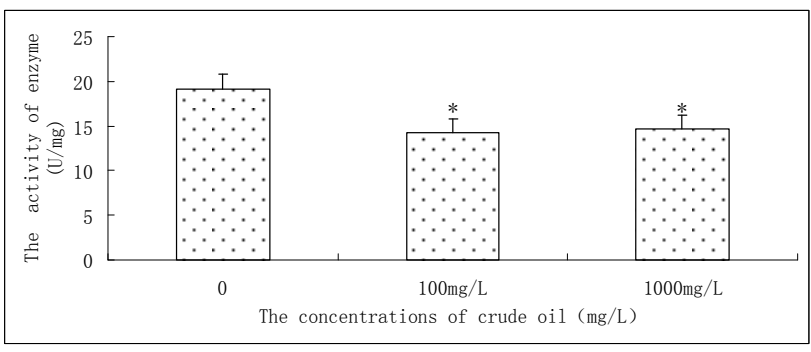

Fig. 4-2 The Activities of GOT in muscle of P. vannamei

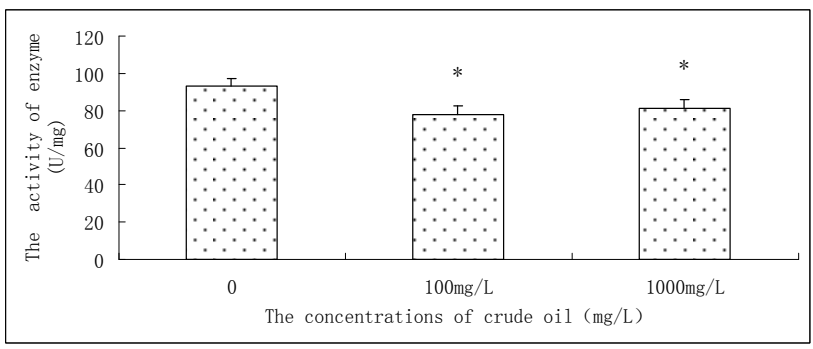

Fig.4-3 The Activities of AHH in muscle of P. vannamei

\section{Discussion}

In the results of determination of enzyme activity, oil stress can work on DNA fracture in body, lipid peroxidation, enzyme inactivation and a series of oxygen stress and that can affect lipid oxidation in the body seriously. Therefore the activities of three kinds of enzyme had a significant reduction. However with the increase of concentrations of oil, the activities of three kinds of enzyme have significantly improvement. Oil has an effect on the activity of SOD, AHH and GOT in body these three enzymes can be used as the indicators of water quality environmental monitoring.

\section{Acknowledgment}

This research was supported by NSFC U1133005; The natural science foundation of Hebei Province(D2013201105); The Education Department of Hebei province key project(2013-77); State Education Ministry (SRF for ROCS, SEM2014); Hebei Characteristics of Seafood Innovation Team of Modern Agro-industry Technology Research System; Projects of coastal habitat restoration in Qinhuangdao (Provincial Science and Technology Department, No. 15273303D); 
Hebei Provincial Key Laboratory of operating subsidy (item number: 14967611D). Funded by Heibei Province construction project in Strong and characteristic disciplines of biology;Funded by Hebei Province project for cultivating national key disciplines in biology; Funded by Hebei University construction project for comprehensive strength promotion of Midwest colleges and universities.

\section{References}

[1] A.I Campa-Córdova, N.Y Hernández-Saavedra,F Ascencio,Superoxide dismutase as modulator of immune function in American white shrimp (Litopenaeus vannamei) . Comparative Biochemistry and Physiology Part C: Toxicology \& Pharmacology,Volume 133, Issue 4, December 2002, Pages 557-565

[2] Hai-Hong Huang, Xiao-Lin Liu.Immune response of Litopenaeus vannamei after infection with Vibrio harveyi. Aquaculture,Volumes 406-407, 25 August 2013, Pages 115-120

[3] F. Sánchez, F. Velasco, J.E. Cartes,Monitoring the Prestige oil spill impacts on some key species of the Northern Iberian shelf.Marine Pollution Bulletin,Volume 53, Issues 5-7, 2006, Pages 332349.

[4] Sergei Bogovski,Vladimir Muzyka,Boris Sergeyev.Biomarkers of carcinogenic contaminants in baltic flounder ( Platichthys flesus ) [J].Environmental Science and Pollution Research, 2002, 9 (1):15-18.

[5] A.I Campa-Córdova, N.Y Hernández-Saavedra,F Ascencio,Superoxide dismutase as modulator of immune function in American white shrimp (Litopenaeus vannamei). Comparative Biochemistry and Physiology Part C: Toxicology \& Pharmacology, Volume 133, Issue 4, December 2002, Pages 557565.

[6] Araneda M,Perez E P,Gasca-Leyva E.White shrimp Penaeus Vannamei culture in freshwater at three densities:Condition state based on length and weight[J].Aquaculture,2008,283:13-18.

[7] DiG iulio R T, W ashburn P C, W enning R J et al. Biochem ical reponses in aquatic animals: a review of de-term inants of oxidative stress. Environ. Toxicol. Chem., 1989, 8: 1103 1123.

[8] F. Sánchez, F. Velasco, J.E. Cartes,Monitoring the Prestige oil spill impacts on some key species of the Northern Iberian shelf.Marine Pollution Bulletin,Volume 53, Issues 5-7, 2006, Pages 332349.

[9] Guo Qiao, Deok Chan Lee, Sung Ho Woo et al.. Microbiological characteristics of Vibrio scophthalmi isolates from diseased olive flounder Paralichthys olivaceus[J]. Fisheries Science, 2012, 78(4): 12-18.

[10]Hai-Hong Huang,Xiao-Lin Liu.Immune response of Litopenaeus vannamei after infection with Vibrio harveyi. Aquaculture,Volumes 406-407, 25 August 2013, Pages 115-120.
[11]Hyo Jin Leea, Gi Beum Kima.Genotoxicity and development effects of brominated flame retardant PBDEs and UV-exposed PBDEs on grass shrimp (Palaemonetes pugio) embryo[J]. 2012, 64(12): 2892-2895.

[12] Jianing Pua, Peter J. Bechtelb, Subramaniam Sathivela.Extraction of shrimp astaxanthin with flaxseed oil: Effects on lipid oxidation and astaxanthin degradation rates [J]. 2010,107(4): 364371.

[13] Jianing Pua, Peter J. Bechtelb, Subramaniam Sathivela.Extraction of shrimp astaxanthin with flaxseed oil: Effects on lipid oxidation and astaxanthin degradation rates[J].2010,107: 23-28.

[14] Lemaire P, M attewsA Fòrlin L. K ivingstone D R. Stimulation of Oxyradical Production of hepaticm icro-somes of flounder (Platichthys flesus) and Perch (Perca fluviatilis) by model and pollutant xenobiotics. Arch. Environ. Contam. Toxicol., 1994, 26: 191 200.

[15] Lemaire P, M attewsA Fòrlin L. K ivingstone D R. Stimulation ofOxyradicalProduction of hepaticm icro-somes of flounder (Platichthys flesus) and Perch (Perca fluviatilis) by model and pollutant xenobiotics.Arch. Environ. Contam. Toxicol., 1994, 26: $191 \sim 200$.

[16] S. Klomklao,S. Benjakul,W. Visessanguan.Comparative studies on proteolytic activity of splenic extract from three tuna species commonly used in Thailand. Journal of Food Biochemistry . 2004 28(5): 355-372.

[17] Sergei Bogovski,Vladimir Muzyka,Boris Sergeyev.Biomarkers of carcinogenic contaminants in baltic flounder ( Platichthys flesus $)[\mathrm{J}]$.Environmental Science and Pollution Research, 2002, 9 (1):15-18.

[18] Stegeman J J, M arius Broumer, R T DiG iulio et al. $\mathrm{M}$ olecular responses to environmental contam ination:enzyme and protein synthesis as indicators of chem ical exposure and effects. In Biomarkers, Biochem ical,Physiological andHistologicalM arkers ofAnthropogenic Stress, (HuggettR. A., K imerle P. M., M ehrleP. M. Jr\& Bergman, H. L., eds). Lew is Publishers, Boca Raton,. Florida, 1992: 235 335. 